\title{
Breathing for two: pregnancy, asthma and respiratory failure
}

\author{
Mina Gaga and Eleftherios Zervas
}

Affiliations: $7^{\text {th }}$ Respiratory Medicine Dept, Athens Chest Hospital "Sotiria", Athens, Greece.

Correspondence: M. Gaga, $7^{\text {th }}$ Respiratory Medicine Dept, Athens Chest Hospital “Sotiria”, 152 Mesogeion Ave, Athens 11527, Greece. E-mail: minagagadyahoo.com

0

@ERSpublications

Adherence to required asthma medication during pregnancy ensures asthma control, a safe delivery and a healthy baby http://ow.ly/sZgvy

Most women will happily swallow vitamins or iron supplements prescribed by their doctor during pregnancy and feel that these help build a strong baby, but are very reluctant to use other medications, and feel that these will jeopardise their fetus and produce congenital abnormalities. So, most expectant mothers will opt to forego medications they need, believing that this will be best for their baby. Sometimes, it is not just the pregnant women but doctors as well who may be unsure about the risks and benefits of drugs during pregnancy, and may fail to convince their patients about the importance of adhering to a required treatment regimen.

Unquestionably, all medications should be prescribed with caution during pregnancy, especially in the first trimester, and data may be controversial even regarding the safety of widely prescribed supplements such as folic acid, maternal use of which has been associated with increased prevalence of childhood wheeze at 1 year of age although no other adverse outcomes have been reported [1]. Nevertheless, data show that uncontrolled chronic diseases are associated with adverse perinatal outcomes and, therefore, avoiding the use of tested safe medications increases the risk for both mother and fetus [2-6]. One of the most common chronic diseases affecting pregnant women is asthma, affecting up to $8.4 \%$ of pregnancies [2-4]. The goal of asthma treatment is the control of asthma, defined as having no symptoms, no exacerbations, no limitations of activities and a good quality of life with no future risk. In the case of asthma and pregnancy, the goal of treatment includes not only control of asthma but also a safe delivery and a healthy child. Exacerbations occur much more frequently and are more serious in untreated and uncontrolled disease and, therefore, maintaining control by adhering to the required level of treatment is very important. Numerous studies have shown that inhaled medications used in asthma have a very low risk and are classified as Pregnancy Category B or C by the US Food and Drug Administration [7]. Therefore, the benefit of their use outweighs any possible risk. All current guidelines recommend regular use of asthma medications during pregnancy, according to the level of control, and stress that treatment should continue following the same principles that apply to nonpregnant individuals and should not be altered on the basis of pregnancy but only as required by the level of asthma control $[4,8]$.

In this issue of the European Respiratory Review (ERR), an article by MURPHY and SCHATZ [9] highlights how important asthma medication and adherence to treatment are for a good outcome in pregnancy. These authors have published a number of pivotal articles on asthma and pregnancy, and are leading experts in the field $[10,11]$. They now review the current data and show once again that there is an increased risk of pre-term birth, hospitalisation and death, as well as the child being small for gestational age and low birth weight,

Received: Jan 242014 | Accepted after revision: Jan 242014

Conflict of interest: Disclosures can be found alongside the online version of this article at err.ersjournals.com

Provenance: Submitted article, peer reviewed.

Copyright OERS 2014. ERR articles are open access and distributed under the terms of the Creative Commons Attribution Non-Commercial Licence 3.0. 
particularly among females with moderate-severe asthma who experience exacerbations during pregnancy. Exacerbations may lead to hypoxaemia that can be detrimental to the mother and fatal to the fetus, while management of exacerbations will often require oral steroids and their use is associated with a slight but significant increase in congenital malformations, particularly cleft lip with or without cleft palate. Moreover, preterm birth and intrauterine growth disturbances are strong risk factors for childhood asthma [12].

So it is important to convince expectant mothers that keeping their asthma controlled by regular use of their inhaled medications is necessary for a trouble-free pregnancy, a safe delivery and a healthy baby. In very severe asthma requiring systemic steroids as well as during asthma exacerbations, the benefit of their use outweighs their risk as they prevent and reverse the hypoxaemia that threatens both mother and fetus. However, to convince expectant mothers, physicians must also be convinced to use asthma medications, including oral corticosteroids, appropriately, according to levels of asthma severity and control. In a recent study, MCCALLISTER et al. [13] showed that among asthmatics presenting to emergency care with acute asthma exacerbations, pregnant females were less likely to receive appropriate therapy with systemic corticosteroids $(50.8 \%$ versus $72.4 \%, \mathrm{p}=0.001)$. This attitude leaded to a four-fold increase in the likelihood of re-admission within 2 weeks $(9.7 \%$ versus $2.5 \%, \mathrm{p}<0.05)$.

Asthma must be kept under control during pregnancy: regular follow-up for both asthma and pregnancy, a good patient-doctor relationship, a healthy lifestyle, and adherence to controller treatment are the most effective measures for an uncomplicated pregnancy, a safe delivery and a healthy child. Reassuring information regarding the safety of asthma medication and sound data on the importance of asthma control during pregnancy, as shown in the Clinical Year in Review article by MuRPHY and SCHATZ [9], help doctors better understand the risks and benefits of the use of medication during pregnancy and push medical attitudes in the right direction. In a recent study from a cohort of more than 500000 deliveries in the USA, the prevalence of asthma and asthma medication use during pregnancy was assessed between 2001 and 2007 [14]. In this large cohort, asthma prevalence among pregnant females increased from 5.5\% in 2001 to $7.8 \%$ in 2007, probably reflecting not only the increased burden of asthma but also the awareness of healthcare professionals regarding the disease. More important was the finding that maintenance medication use doubled during the study period, while rescue-only use decreased significantly (from $7.4 \%$ to $5.8 \%$ ).

Asthma exacerbations may sometimes be very severe and require admission to an intensive care unit and ventilatory support, but asthma is not the only respiratory condition that may threaten pregnancy. Acute respiratory failure (ARF), usually due to infections, eclampsia, pulmonary oedema, as well as more chronic thoracic conditions such as neuromuscular disorders and kyphoscoliosis, is a major risk to a pregnancy. ARF occurs in $<0.1 \%$ of pregnancies, but it is one of the most common indications for obstetric admissions to the intensive care unit and carries high morbidity and mortality for both mother and fetus [15]. Treatment goals during respiratory failure in the pregnant female are similar to those outside pregnancy: to maintain adequate ventilation and to provide haemodynamic and nutritional support, and give the patient time to recover. Additionally, the obstetrician will need to monitor fetal status and help to determine the best timing for delivery. ARF may require ventilatory support but mechanical ventilation carries higher risks during pregnancy: pregnancy-associated oedema of the upper airways increases the risk of difficult airway and intubation failure, while benzodiazepines needed for sedation may adversely affect the baby's respiration. In order to avoid intubation and sedation, noninvasive ventilation (NIV) has been used with good results. In this issue of the ERR, ALLRED et al. [16] present two new case reports and review the literature data on the use of NIV during pregnancy. Their patients developed acute respiratory distress syndrome (ARDS), were placed on NIV, improved and were successfully weaned after 2 and 4 days respectively, avoiding intubation. They both delivered preterm but otherwise healthy babies. The trigger of ARDS was viral infection in the first case, while rupture of the membranes and separation of the chorioamniotic fluid, followed by use of tocolytics, antibiotics and steroids, preceded ARDS in the second. Tocolytics have been associated with pulmonary oedema in pregnancy but the second patient may have suffered an immune reaction or a co-existing pneumonia.

In the literature, cases of ARDS and respiratory failure in pregnancy have been attributed to infections such as community-acquired pneumonia and influenza A infection, sepsis, use of trans-retinoic acid, and acute chest syndrome in sickle cell anaemia. There has been no randomised, controlled study on the use of NIV in pregnancy and the ethical issues associated with such a study make it more or less impossible to conduct. Therefore, so far, there are only case reports, which are however positive and encourage the use of NIV in ARF in pregnancy.

Around 25 such case-reports have been published to date and are reviewed by ALLRED et al. [16], all of them with favourable outcomes for both mother and fetus. One of the cases reviewed [17], is that of a young patient in her 16th week of pregnancy, who had both an asthma attack and community-acquired pneumonia. She subsequently developed hypoxic respiratory failure and was successfully treated using NIV. 
The authors conclude that in carefully selected and closely monitored pregnant females, NIV may be considered a reasonable and safe option for the management of ARF, and provides the patient the chance to avoid intubation and its complications. AlLred et al. [16] highlight the advantages of this noninvasive approach.

In conclusion, hormonal, anatomical and physiological changes during pregnancy increase the work of breathing and make breathing for two - or for more than two - quite a task. However, asthma should not cause any additional problems as pregnant asthmatics and doctors now have safe medications and the knowledge to use them appropriately. Asthma control, through the use of controller medications in the recommended step-wise approach, can minimise the risks for both mother and fetus. In the rare cases where asthma attacks or other causes lead to ARF, NIV is an effective way of delivering air for two.

\section{References}

1 Bekkers MB, Elstgeest LE, Scholtens S, et al. Maternal use of folic acid supplements during pregnancy, and childhood respiratory health and atopy. Eur Respir J 2012; 39: 1468-1474.

2 Tegethoff M, Olsen J, Schaffner E, et al. Asthma during pregnancy and clinical outcomes in offspring: a national cohort study. Pediatrics 2013; 132: 483-491.

3 Kwon HL, Belanger K, Bracken MB. Asthma prevalence among pregnant and child bearing-aged women in the United States: estimates from national health surveys. Ann Epidemiol 2003; 13: 317-324.

4 National Heart, Lung, and Blood Institute, National Asthma Education and Prevention Program Asthma and Pregnancy Working Group. NAEPP expert panel report. Managing asthma during pregnancy: recommendations for pharmacologic treatment - 2004 update. J Allergy Clin Immunol 2005; 115: 34-46.

5 Negrato CA, Mattar R, Gomes MB. Adverse pregnancy outcomes in women with diabetes. Diabetol Metab Syndr 2012; 4: 41.

6 ACOG Committee on Practice Bulletins. ACOG practice bulletin. Clinical management guidelines for obstetriciangynecologists. Number 60, March 2005. Pregestational diabetes mellitus. Obstet Gynecol 2005; 105: 675-685.

7 Global Initiative for Asthma. Global Strategy for Asthma Management and Prevention. http://ginasthma.org/local/ uploads/files/GINA_Report_March13.pdf Date last updated: 2012

8 Gaga M, Oikonomidou E, Zervas EN. Papageorgiou-Georgatou. Asthma and pregnancy: interactions and management. Breathe 2007; 3: 267-276.

9 Murphy VE, Schatz M. Asthma in pregnancy: a hit for two. Eur Respir Rev 2014; 23: 64-68.

10 Murphy VE, Namazy JA, Powell H, et al. A meta-analysis of adverse perinatal outcomes in women with asthma. BJOG 2011; 118: 1314-1323.

11 Namazy JA, Murphy VE, Powell H, et al. Effects of asthma severity, exacerbations and oral corticosteroids on perinatal outcomes. Eur Respir J 2013; 41: 1082-1090.

12 Källén B, Finnström O, Nygren KG, et al. Association between preterm birth and intrauterine growth retardation and child asthma. Eur Respir J 2013; 41: 671-676.

13 McCallister JW, Benninger CG, Frey HA, et al. Pregnancy related treatment disparities of acute asthma exacerbations in the emergency department. Respir Med 2011; 105: 1434-1440.

14 Hansen C, Joski P, Freiman H, et al. Medication exposure in pregnancy risk evaluation program: the prevalence of asthma medication use during pregnancy. Matern Child Health J 2013; 17: 1611-1621.

15 Mighty H. Acute respiratory failure in pregnancy. Clin Obstet Gynecol 2010; 53: 360-368.

16 Allred CC, Esquinas AM, Caronia J, et al. Successful use of noninvasive ventilation in pregnancy. Eur Respir Rev 2014; 23: 142-144.

17 Dalar L, Caner H, Eryuksel E, et al. Application of non-invasive mechanical ventilation in an asthmatic pregnant woman in respiratory failure: a case report. J Thorac Dis 2013; 5: 97-100. 